\title{
The Existence of Kolok in the Inscription Script of Bengkala Village, Kubutambahan Subdistrict, Buleleng Regency (Perspective of Hindu Theology)
}

\author{
Pande Wayan Renawati \\ \{panderena@gmail.com\}
}

Program pascasarjana IHDN Denpasar

\begin{abstract}
Bali is known as the Dewata island with several palm-leaf manuscripts. These are relics of the ancient landmarks which should be considered and preserved. The palm-leaf manuscripts cover a variety of things such as usada, wariga, and also as an inscription made into a script or copied into both the speech and text to ease reading. Also, the manuscripts spread across all regions in Bali, and preserved by the government through the Provincial and Regency Culture Office. Similarly, an inscription was discovered in Bengkala Village, Kubutambah Subdistrict of Buleleng Regency in the northern part of Bali. Therefore, the purpose of this study was to determine and analyze the substance contained in the Bengkala Village Inscription, and the implementation of its contents among the kolok residents of the village. The qualitative method was used to carry out this study and data collection was through documentation, in the form of inscriptions script from the kolok residents. The results showed that the substance was the size of Bengkala inscription, the contents of the metal has its translation and the stone inscriptions has an explanation. Furthermore, based on its implementation among the kolok residents, there was a policy among the leaders to helpresidents keep it right from the royal era. In conclusion, the position of leader related to the Bengkala inscription, the types of taxes, the prohibited and permissible matters, all play a major role in its implementation.
\end{abstract}

Keywords: Existence, kolok residents and contents and implementation of Bengkala inscription.

\section{Pendahuluan}

Keberadaan penduduk baik di wilayah Bali bahkan di belahan dunia mana pun tidaklah sama. Ada penduduk yang normal dan ada pula penduduk yang hanya memiliki keterbatasan untuk bisa menyaksikan indahnya alam namun tidak bisa mendengar maupun berbicara atau disebut dengan tuli bisu atau kolok. Hal ini mungkin terjadi dan terungkap dalam Prasasti Desa Bengkala. Namun perlu juga dipahami pemaknaan prasasti itu menurut id.m.wikipedia.org disebutkan bahwa.

Sehubungan dengan warga kolok yang terdapat dalam prasasti tersebut, dengan keterbatasan yang ada telah menempati wilayah Desa Bengkala sejak masa lalu dengan 
berbagai pendapat. Jumlah warga kolok hingga kini mencapai 48 orang. Dengan demikian warga kolok itu mempunyai hak azasi dan kedudukan yang sama sebagai manusia Indonesia pada umumnya sesuai dengan amanat Undang-Undang Dasar 1945. Warga kolok dalam pelaksanaan kehidupan sehari-hari, utamanya saat bekerja dan menjalani kehidupan terlihat hampir mendekati sempurna layaknya manusia normal pada umumnya namun sesungguhnya situasinya amat terbatas. Untuk keturunan, dengan keadaan itu antar pribadi kolok jika menikah akan menghasilkan warga kolok yang sama, pun demikian ada pula anak yang ke tiga normal dan ke empat kembali kolok. Tapi jika salah satunya warga kolok maka akan menghasilkan keturunan yang normal semua. Mengenai tata cara berkomunikasi, orang yang normal pada umumnya untuk bergaul dengannya harus belajar berbahasa kolok terlebih dahulu sehingga lebih mudah untuk berkomunikasi. Untuk mempelajari bahasa warga kolok selain dengan bicara langsung dengannya juga harus bisa menggerakkan dengan bahasa tubuh/body language dengan kode tertentu memaknai suatu maksud sesuai dengan buku dialog warga kolok yang penulis buat beserta tim. Sebab pada buku tersebut telah diFigkan melalui peragaan singkat untuk komunikasi ringan saja, sedangkan untuk dialog dengan kalimat yang panjang bukunya masih dalam proses pembuatan. Diharapkan dengan buku dialog singkat itu setidaknya bisa membantu komunikasi dengan warga kolok dalam melengkapi pendataan.

Dari situasi tersebut ada beberapa hal yang mesti dikaji untuk diketahui kedalaman prasasti tersebut, sehingga bisa mendapatkan jawaban sesuai dengan harapan. Melalui latar belakang di atas, tujuan dari penelitian ini adalah untuk mengetahui dan menganalisis substansi yang terdapat pada naskah Prasasti Desa Bengkala tersebut. Serta untuk mengetahui dan menganalisis implementasi terhadap isi naskah prasasti warga kolok di Desa Bengkala tersebut.

\section{Metode}

Penelitian ini dilakukan di desa Bengkala kecamatan Kubutambahan kabupaten Buleleng. Penelitian ini menggunakan metode kualitatif untuk mengetahui dan menganalisis substansi yang terdapat pada naskah Prasasti Desa Bengkala tersebut. Serta untuk mengetahui dan menganalisis implementasi terhadap isi naskah prasasti warga kolok di Desa Bengkala tersebut. Data dalam penelitian ini adalah naskah prasasi desa Bengkala. Teknik pengumpulan data dalam penelitian ini adalah dengan menggunakan dokumentasi yang berupa naskah prasasi desa Bengkala. Setelah data dikumpulkan, kemudian data diolah dan dikaji.

\section{Hasil Dan Diskusi}

Berdasarkan tujuan dan hasil analisis, maka diperoleh hasil penelitian yang dapat dijelaskan di bawah ini.

\subsection{Substansi Yang Ada pada Prasasti Desa Bengkala}

Prasasti Desa Bengkala merupakan beberapa lempeng prasasti yang ditemukan oleh Kaki Sawit tahun 1971. Letak penemuannya di tebing Tukad Daya sekitar Tibuan Lantang yang masih berbatasan dengan wilayah Bengkala. Prasasti ini terbuat dari logam tembaga yang 
terdiri atas enam (6) lempeng. Keenam lempeng prasasti ini berukuran panjang $40 \mathrm{~cm}$, lebar 9 $\mathrm{cm}$ dan tebal $2 \mathrm{~mm}$. Prasasti ini merupakan prasasti lengkap dari bagian awal dan akhir yang bertuliskan Aksara dan Bahasa Jawa Kuna juga. Pada lempeng I prasasti ini ditulis atau ditatah enam (6) baris aksara hanya ada pada satu sisi. Lempeng II, III, IV, V, dan VI ditatah pada kedua sisi masing-masing enam aksara. Khusus pada lempeng VIb yang merupakan bagian akhir ditatah empat (4) baris aksara. Dengan demikian seluruhnya terdiri atas 56 baris aksara. Berikut tempat penemuan prasasti di tebing tersebut.

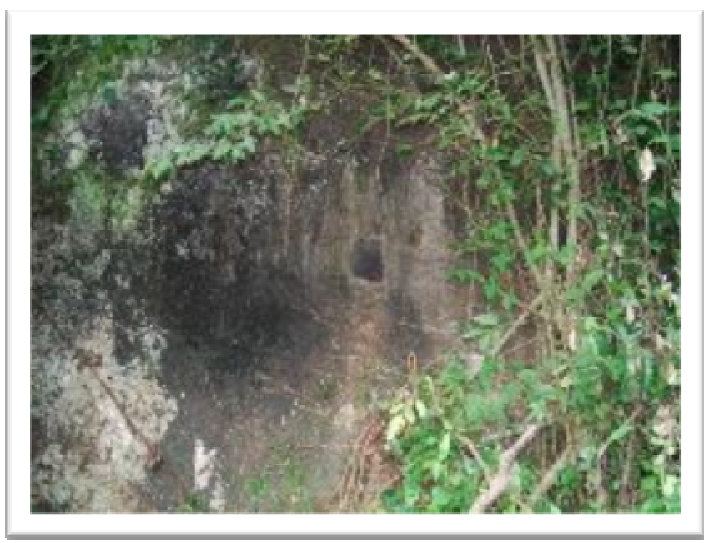

Fig 1. Lubang Prasasti.Di bawah ini merupakan lempeng prasasti yang diperoleh di lubang sekitar tebing Tukad Daya sekitar Tibuan Lantang, dengan masing-masing lempengnya dalam bahasa Indonesia sebagai berikut.

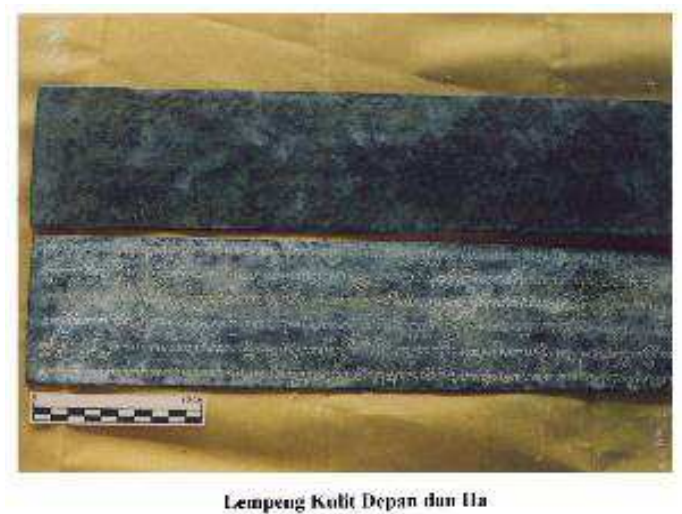

Fig 2. Lempeng Kulit Depan dan IIa 


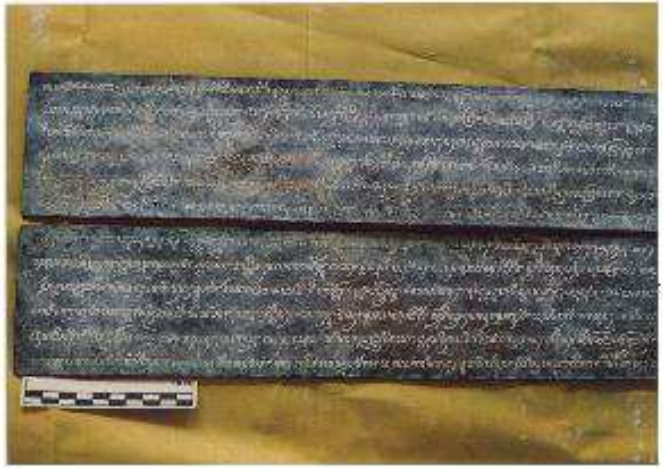

I.empeng It than IIt

Fig 3: Lempeng Ib dan IIb

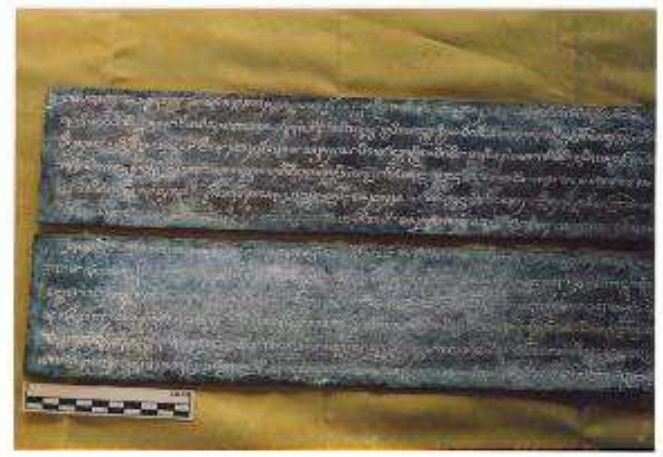

Lempeng IIIa dan IVb

Fig 4 Lempeng IIIa dan IVb

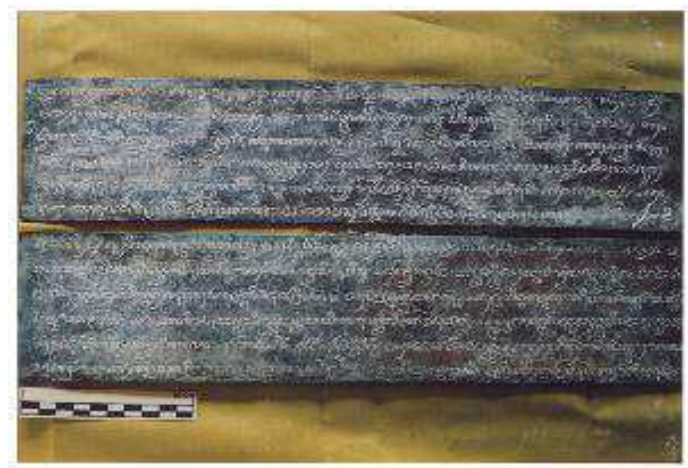

1.empeng IIIh dun It's

Fig 5: Lempeng IIIb dan IVa 


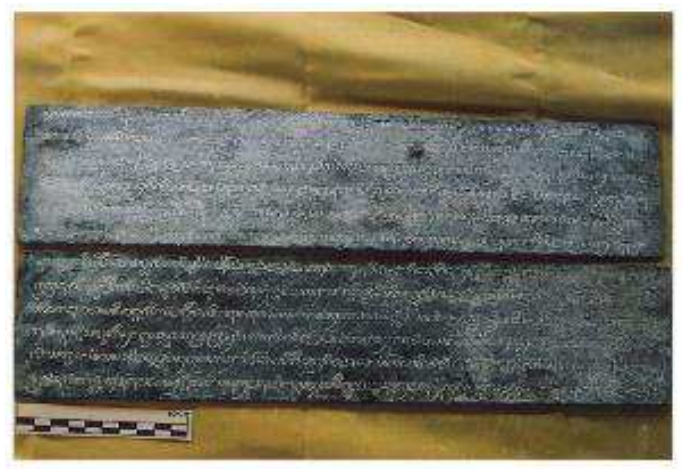

Lentpeng va dau v la

Fig 6: Lempeng Va dan Vla

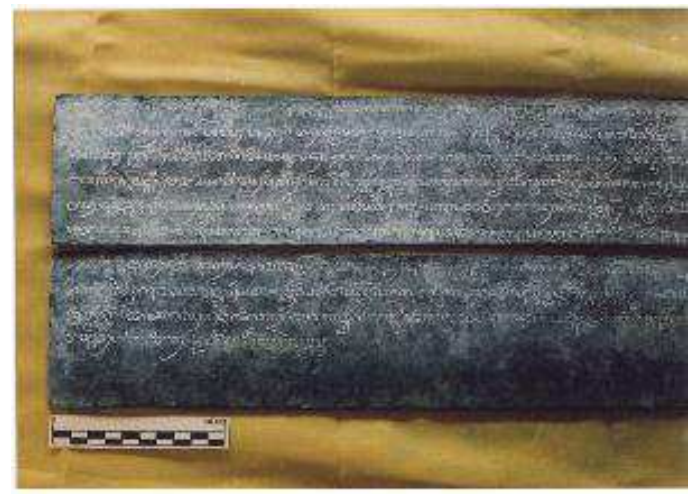

Lempeng vh dan $v 1 \mathrm{~b}$

Fig 7. Lempeng $\mathrm{Vb}$ dan $\mathrm{VIb}$

Isi Prasasti Desa Bengkala dapat diterjemahkan sebagai berikut:

a) Alih Bahasa

2a 1. Padrwyahajyan (perpajakan), oleh karena masyarakat disana sesungguhnya adalah kelahiran orang orang wesya harta miliknya merupakan sarana utama dalam segala karya yaitu menegakkan dharma dan menciptakan artha dan kama, terlebih pula merupakan mata pencaharian masing-masing

2. serta terwujudnya kesejahteraan di Pulau Bali yang seluruhnya merupakan kekuasaan raja Jayapangus Lancana, maka ada kebijaksanaan baginda Sri Maharaja Sri Samajaya, dengan mendengar (memperhatikan) isi kitab Manawa

3. kamandaka dan mengambil bagian yang berguna dalam kaitannya dengan mengusahakan kekokohan Negara yang diperintahkannya, serta demi tetap tegaknya Negara dan demi kewibawaan baginda sebagai raja penguasa dunia, raja diantara para raja

4. dari suatu kerajaan, sebagai pelindung Negara. Itulah sebabnya maka dinyatakan dengan jelas oleh baginda Sri Maharaja segala padrwayahajian daripada masyarakat Bengkala sewilayah desanya, dengan maksud agar tidak ditentangkan

5. sampai kelak dikemudian hari. Itulah sebabnya mereka diberi menjaga prasasti pegangan dan tuntunan dalam bertindak dan harus dijaga untuk mengokohkan dirinya dan menunggu masyarakat sebagai wilayah swatantra (otonomi) 
6. oleh karena itu, tidak dikenai berbagai macam biaya dan tidak kena berbagai macam pajak oleh para wuluwulu (nama jabatan) terutama watun palbur pada saat upacara besar dan

2b1. Pajak peternakan kuda, oleh karena memang tidak kena dari awal sebagaimana diwariskan dari dulu sampai sekarang. Adapun kemudian pembayaran drwyahaji bagi masyarakat Bengkala yang berdiam di wilayah desanya, mereka dipunguti 4 masaka 2 kupang masing masing tidak boleh

2. digandakan, hendak dibayar kepada samgat bengkala atau samgat manasa setiap hari ketiga bulan wesaka (sasih kadasa). Tidak dikenakan panglya palaris, tidak kena pacaksu, pangiwo serta tmwan dan segala macamnya, tidak.

3. dikenai pinta manumbas pada saat pembayaran drwyahaji pada hari kesembilan yang besar di bulan magha (sasih kapat) sebagaimana berlaku semenjak dulu. Adapun padrwahajian berupa palbur masing masing 2 kupang tidak boleh dilipatgandakan.

4. supaya dibayar kepada beliau sang admak akmitan apigajih ser tunggalan setiap hari ketiga di bulan pangiwo serta tmwan tidak kena panglyo palaris pada saat pembayaran

5. berbagai macam drwahaji seperti pinanen, parp agar membayar 2 kupang masingmasing jangan ditambah-tambahi hendaknya dibayar kepada sang admak akmitan apigajih ser tunggalan setiap bulan karttika seperti dulu dulu

6. Tidak kena pacaksu pangiwo serta tmwan tidak kena panglyo palaris, tidak kena pinta panumbas pada waktu pembayaran berbagai macam drwyahaji termasuk pinta panumbasen. Kemudian tidak padrwyahaji

3a1. Palunak, hendaknya selalu ingat dengan takaran asam beserta bijinya yang diserahkan kepada sang admak akmitan apigajih ser tunggalan. Demikianlah apabila dilaksanakan pemungutan pajak wilang di desanya supaya membayar

2. sebanyak 2 kupang masing - masing pintu pakarangan, dengan tambahan 1 kupang tiap-tiap pintu pakarangan baru. Tidak boleh kurang dan tidak boleh lebih agar dibayar kepada beliau sang admak akmitan apigajih ser tunggalan tiap bulan sekali sebagaimana kebiasaan dulu

3. pajak temwan 1 masaka, partikel tanah 1 masaka, pangiwe 2 kupang tidak boleh ditambah-kurangi. Apabila ada yang berani melakukan pengurangan terhadap hak sang admak akmitan apigajih jelas tidak sesuai dengan anugrah baginda

4. Sri Maharaja, tidak boleh tidak dijatuhi hukuman sebanyak 3 masaka suwarna 2 masaka. Selanjutnya mereka tidak kena wilang tandayu kepada ser tunggalan, terlebih lagi yang diserahkan ke wijayapura, akan tetapi cukup dipermaklumkan di Manasa

5. mengenai pajak wilang tersebut. Adapun drwyahaji yang harus diserahkan di Babut supaya membayar 1 masaka masing-masing tidak boleh ditambah-tambahi agar dibayar kepada beliau di Babut setiap Purnama bulan cetra 
6. Kemudian, masyarakat Bangkala sewilayah desanya diperkenankan pergi ke pasar menurut kehendaknya tidak akan ditegur oleh tapiaji, tidak dipunguti lagam rwang (semacam cukai). Mereka boleh memelihara itik tidak akan diambil oleh nayakan

3b 1. Jawa, tidak kena pacadar, panila, pajahit serta pabhangkudu dan lain lain semacam itu. Demikian pula mereka diijinkan memelihara asu tugel dan pirung tidak akan diambil oleh nayakan buru dan tidak dikenai posyan

2. Tambahan pula mereka diperkenankan mengadakan sambungan di sebidang tanah dalam lingkungan bangunan suci atau sekitarnya pada awal upacara sekiranya hal itu memang diperlukan. Demikian pula seberapa banyak mengadakan sambungan tidak dibatasi jumlahnya tidak perlu.

3. dimintakan ijin, tidak adegana (permakluman) tidak boleh memungut ongkos taji maupun ongkos wulang (benang). Demikianlah apabila ada tempat suci (keluarga pedukunan berumah di desanya, mereka tidak ditunjuk untuk tugas-tugas upacara di Pujung dan Patatahan. Mereka tidak dikenai

4. buncang haji (kerja rodi), anyam-anyaman, tidak kena paclak serta pawija, pakabuddhi serta rot. Mereka diperkenankan datang ke desa lain tidak akan ditegur oleh watek ser walyan

5. serta hulukayu pujung, tidak disalahkan dan tidak kena laganing hnu (perjalanan pajak). Demikianlah apabila ada katyagan (semacam pesraman) di wilayah desanya, mereka boleh tidak menghaturkan saji sajian pantibhumi, tidak akan dipermasalahkan oleh watek

6. kuturan, tidak kena padesi serta pacaru. Selanjutnya apabila ada warga desanya berjumpa dengan putra wiku resi, janda atau duda wiku resi, mereka tidak mesti menyerahkan bunga yang cepat layu maupun yang tahan lama.

4a 1. Terlebih lebih para wiku resi diperbolehkan berdiam membuat rumah di dekat rumahrumah penduduk desa. Tidak akan dianggap seperti belaku seperti anjing belang. Tidak akan dikenai denda wsi oleh kuturan. Selanjutnya masyarakat di Bangkala sewilayah desa dibolehkan

2. menyembelih kerbau, sapi yang memakan segala yang dipelihara di desanya tidak dibatasi jumlah yang dibunuhnya, tidak perlu dimintakan ijin kepada beliau sang admak akmitan di Bangkala serta kepada sang admak akmitan apigajih ser.

3. tunggalan serta kepada pejabat kerajaan apalagi kehadapan baginda Sri Maharaja, tidak mengakibatkan kesalahan tidak kena padilebleb. Selanjutnya masyarakat Bangkala sewilayah desa

4. diperbolehkan mencari sumber air, diperbolehkan membuat atau memperluas kali untuk pengairan tanah-tanahnya serta mencari atau mengambil air dimanapun sumbernya untuk penataan tanahnya serta mengadakan system pembagian air yang dialirkan ke sawahnya 
5. serta guguran tanah di sawahnya, mereka boleh menebang kayu. Kayu larangan terutama kemiri, beringin, boddi, mindi apabila kayu-kayu itu salah satu merusak yaitu menaungi sawah, kebun, lahan padi gaga, pagar rumah terlebih tempat pertemuan, untuk memperbaiki

6. keadaan jalan, walaupun dipotong sampai ke akar akarnya tidak akan disalahkan maupun dikenai ganagana. Demikianlah apabila ada kerbau, sapi, babi, kambing mati dikali atau dalam semak belukar tidak perlu tarubana

4b 1. Hendaknya dipermaklumkan kepada para tetangga di desanya dan tidak perlu dilaporkan ke Manasa terutama kepada beliau sang admak akmitan apigajih ser tunggalan tidak akan ditimpakan

2. kesalahan. Apabila lembu, kuda mati dan terutama orang mati salah pati di desanya supaya dilaporkan kepada beliau sang admak akmitan apigajih ser tunggalan beserta kepada beliau sang admak akmitan

3. Bengkala. Apabila hal tersebut dilaporkan tidak dikenai biaya pelaporan dan berbagai macam saji sajian pelaporan berkaitan dengan hal itu. Apabila ular sawah mati ditempatnya, sama sekali tidak usah dilaporkan tidak akan menimbulkan

4. kesusahan bagi masyarakat, sebab tidak patut disesali akan berpergian atau kematiannya. Apabila mereka tidak mengetahui tentang adanya orang mati salah pati di wilayah desanya atau terlebih dahulu diketahui oleh pejabat caksu wruh, mereka dikenakan dosa

5. tamtam 2 masaka 2 kupang masing masing tidak dan tidak kenai berbagai macam saji sajian dan kelengkapannya. Demikianlah apabila ada tanda tanda bahaya besar di desanya mereka supaya menyerahkan partikel tanah masing masing 1 masaka

6. apabila buruk akibatnya mereka supaya memberikan daksina 1 masaka masing masingnya, tidak dikenai saji saji dan kelengkapannya, apabila ada

5a 1. Warga desanya menemukan kambing yang tidak diambil oleh suruhan atau abdi dewa, kambing tersebut diambil secara paksa oleh salah seorang warga masyarakat Bangkala orang tersebut boleh direbut dan tidak mengakibatkan kesalahan. Demikianlah apabila

2. ada warganya yang termasuk penduduk desa salah jalan berbuat dosa ganagana segala jenis dosa diperbuatnya seperti mencuri, merampok, memukul, menghadang (menyamun), membunuh secara sadis, menyiksa

3. mengamuk, merampok, memperkosa, berkhianat, menyihir, meracun, mengancam, menyuruh menjilat lidah (berbohong). Berkata kasar, kejahatan akibat perbuatan tangan, berbuat jahat secara sembunyi seperti labu merambat di halaman, darah tercecer

4. dijalan, mayat berembun, segala kejahatan yang diancam dengan denda, berbagai kejahatan besar. Tidak kena tandas tutan beserta ludan oleh beliau sang admak akmitan apigajih, ser tunggalan serta sang admak akmittan 
5. bangkala, tidak kena berbagai macam saji sajian dan kelengkapannya. Akan tetapi mereka dibebani membayar 1 masaka, pamli 2 kupang, temuan 2 kupang, untuk keperluan pargapan membayar 1 kupang babini dan kamasan membayar

6. 3 saga pada setiap hari kesembilan, tidak dipungut magha. Demikianlah apabila dilaksanakan pacaran (pacaruan) supaya membayar 2 kupang tetapi tidak kena pakupat, paremrem, beserta wintang marenyit panglar

5b 1. Turunturun, bakatbakat, serta patimtim, tidak kena papuncagiri, patalitali, pabarangka serta patih, serta tidak kena parangsan, pakasumba, palawe, tidak kena pasanga

2. pasangu, serta pawidi, tidak kena palakar pahatep padurupuling, tidak kena pejah lek, serta pajnumanggala palengawastu, purbwapurbwa dan yang semacamnya. Selanjutnya tidak akan diambil berkenan dengan keadaan dirinya, apabila

3. masih dirundingkan tentang keberadaannya, supaya ia membayar kepada pemimpinnya (nayaka) dan tidak dilecehkan tidak akan dihina dan tidak diusir oleh nayakan rggep. Selanjutnya mereka boleh tidak

4. memberi makanan kepada nayaka pada hari kesembilan yang besar di bulan magha, tidak silahkan tidak dimintai pembeli nasi. Mereka dibolehkan melakukan pekerjaan kotor atau berbahaya beserta mengumpulkan dan mengambil berbagai macam binatang.

5. dari hutam, termasuk unyanunyan (segala sesuatu yang bersifat hiburan) dan tidak perlu meminta ijin. Mereka tidak kena palanting beserta rot dan tidak akan disalahkan. Demikianlah apabila ada temannya (warganya) salah jalan yaiut ingin memperistri dari golongan

6. brahmanawangsa hunjeman juru kling mereka supaya membayar pamucuk 2 kupang, apabila tidak mau membayar pamucuk mereka kena denda 1 masaka untuk masing masing nya, tidak kena saji beserta segala kelengkapannya, oleh karena memang tidak kena

6a 1. Dari awal. Selanjutnya ditentukanlah batas batas wilayah desa pada keempat arah, yaitu batas di timur tukad culikan, batas selatan desa Bangkala adalah batu bulitan pimula, batasnya di

2. barat tukad air raya, batasnya di utara babyara terus berbelok ke timur laut. Demikianlah luas wilayah dari desa Bangkala. Demikanlah isi anugrah baginda

3. maharaja kepada masyarakat Bengkala sewilayah desanya. Adapun para sesepuh masyarakat yang hadir pada saat itu adalah Bapan I Marunggwan beserta Bapan I Timurjati, Bapak I Pahit, Bapan

4. I Kirti, isi prasasti ini telah dipersaksikan dihadapan majelis Paripurna Kerajaan terutama para Senapati lebih lebih bagi para pendeta agama Siwa dan Budda

5. Yang hadir pada saat itu ialah : Sang Senapati Denda bernama Pu hitawasana, Sang Senapati Kuturan bernapa Pu Junarma, Samgat 
6. Manyuratang I Hulu bernama Mada Tan Wringreh, Samgat manyuratang Ajna I Tngah bernama Mtadhara, Samgat Manyumbul bernama Wirajma, Samgat Caksu Karanapura bernama Walaharsa, Samgat

6b 1. Manyuratang Ajna wuntat bernama Margga, Samgat Caksu Karana Kranta bernama Antaraya, Samgat Pituha bernama Jugulpunggung, beliau beliau dari agama Siwa Mpungkwing Hyang Padang bernama Dang Acaryya Agreswara

2. Mpungkwing Banyugaruda bernama Dang Acaryya Wwabuing Jaya, Mpungkwing Binor bernama Dang Acaryya Rsi Taruna, Mpungkwing Makarun Dang Acaryya Indrangsa, Samgat Juru Wadwa bernama Dang Acaryya

3. Brahmandra, beliau beliau dari agama Buddha Mpungkwing Kadhikaran bernama Dang Upadyaya Sarwwawaja, mpungking Kutihanyar bernama Dang Upadyaya Antaraja, Mpungking Bajrasikara Dang Upadyaya Bare Jawa

4. Samgat Mangirengiren Wandami bernama Wangsa prya

b) Prasasti Batu

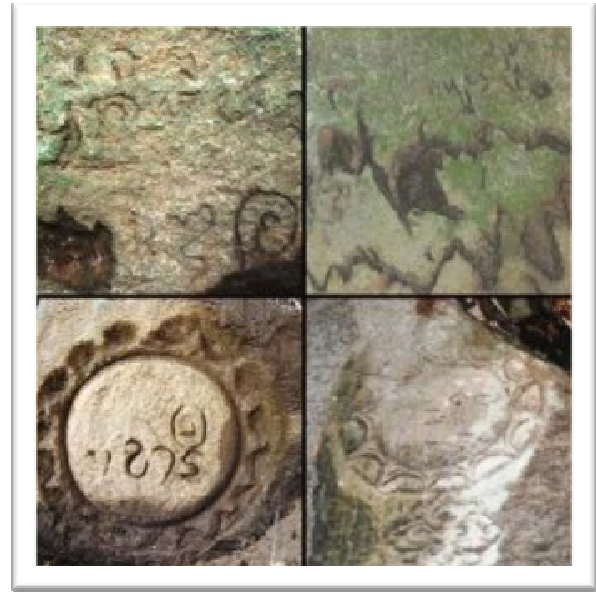

Fig 8: Prasasti Batu

Prasasti batu menggambarkan adanya bentuk matahari, masing-masing batu yang lainnya berisikan tulisan aksara Bali kiranya terbaca tulisan "Lebah".

Seperti diceritakan Kepala Desa Bengkala Made Arpana yang menuturkan, ada keenam lempeng prasasti yang memuat aktivitas masyarakat Desa Bengkala secara umum yakni bertani atau bercocok tanam.

Adapun isi dari keenam lempeng prasasti yang berangka tahun 1103 itu yakni:

1. Bengkala boleh mengatur daerahnya sendiri;

2. Bengkala dibebaskan dari pajak desa;

3. Bengkala boleh memotong hewan apapun untuk upakara;

4. Bengkala boleh memotong pohon keramat sepanjang pohon itu mengganggu;

5. Bengkala boleh mencari sumber air; 
6. Bengkala diberikan mandat untuk menjaga prasasti tersebut.

Menurut https://www.nusabali.com/berita/9019/kupas-isi-prasasti-bengkala-yang-dibuatdi-zaman-raja-jaya-pangus dengan judul Kupas Isi Prasasti Bengkala yang Dibuat di Zaman Raja Jaya Pangus 23 Nov 2016 06:14:51 170 Singaraja Sejarah Prasasti Raja Sri Aji Jaya Pangus

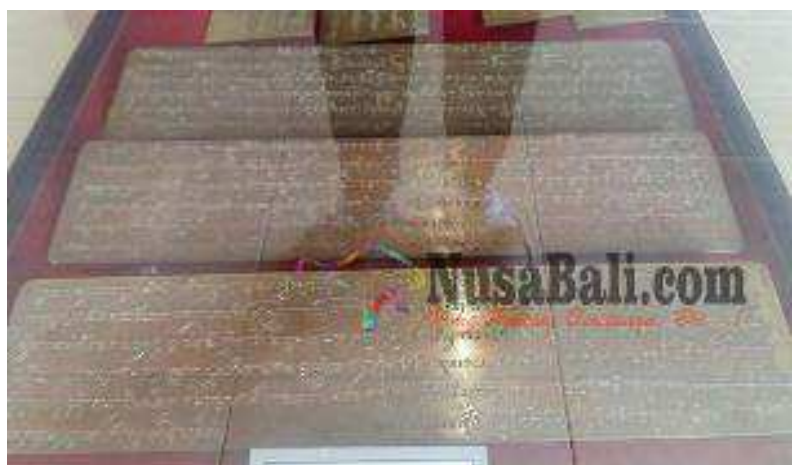

Fig 9: Prasasti Bengkala yang dibuat di zaman Raja Sri Aji Jaya Pangus

Dalam Prasasti Bengkala yang dibuat Tahun Saka 1103 tertulis bahwa zaman itu masyarakat Desa Bengkala ajukan protes dan tuntut keadilan atas perilaku pejabat yang kurang adil dalam pemugutan pajak

\subsection{Implementasi Dari Isi Prasasti Logam Desa Bengkala Terhadap Warga Kolok}

Terkait dengan prasasti logam ada 6 lempeng. Pendalaman akan isi dari Prasasti Bengkala tersebut terdiri atas beberapa unsur seperti Kepemimpinan, Jabatan Para Pemimpin, Jenis pajak, Hal yang Dilarang, dan Hal yang Dibolehkan. Untuk itu dijelaskan sebagai berikut.

\section{a. Kebijakan Raja}

Menghadapnya empat orang sesepuh masyarakat yang hadir saat itu adalah Bapan I Marungguwan, Bapan I Timur Jati, Bapan I Pait, serta Bapan I Kirti, dan raja pun mendengar keluhannya sehingga dibuatnya prasasti oleh para pejabat dan petinggi kerajaan dan terwujudnya Prasasti Bengkala yang harus dijaga oleh penduduknya mulai saat itu dan isinya sebagai pencerminan dalam pembuatan aturan-aturan desa dan segala hal terkait dengan Desa Bengkala. Hingga kini prasasti itu dijaga dan ditempatkan di rumah Klian Adat untuk disimpan dan dipertanggungjawabkan.

b. Jabatan Para Pemimpin Yang terkait dengan Prasasti Bengkala

Jabatan yang ada di lingkungan kerajaan yang berkaitan dengan Desa Bengkala yaitu:

- Senapati adalah raja atau pemimpin tentara.

- Tanda rakryan ring pakirankiran i jro makabehan adalah Majelis Paripurna Kerajaan.

- Nayaka saksi adalah petugas sebagai saksi atau pengamat.

- Nayaken rggep adalah petugas yang mengurus orang-orang yang telah berkeluarga dan menunaikan tugas-tugasnya sebagai anggota krama desa. 
- Samgat adalah sang pemegat (Sang pemutus permasalahan atau yang mencari keputusan), atau petugas yang memutuskan sesuatu.

- Samgat Nayakan Buru adalah pejabat yang bertugas memutuskan permasalahan pembagian waris apabila ada penduduk yang meninggal.

- $\quad$ Sang Admak (yang mengambil), api gajih (yang mengambil gaji). Sang Admak Akmitan Apigajih adalah petugas pemungut pajak.

- $\quad$ Wulu-wulu adalah pejabat yang bertugas mengatur pajak.

- Caksu Wruh adalah pengawas umum yang mengawasi keadaan desa.

Untuk jabatan di Desa Bengkala hingga kini tidak berbeda dengan pejabat pemerintahan di desa -desa di wilayah Bali. Ada Kelian adat, Sekretaris Adat, ada juga Perbekel serta staf desa yang membantu segala kegiatan di desa.

\section{c. Jenis pajak}

Jenis-jenis pajak yang menjadi eksis pada masa Raja Jaya Pangus seperti watun palbur, panglya palaris, pacaksu, pangiwo, pinanen, parp, pinta panumbas, padrwyahaji pakenak, paka wilang, patikel tanah, pangiwe 2 kupang, masaka swarna, wilang tandayu, lagam rwang, asu tugel, pirung, posyam, adegana,buncang haji, paclak, pawija, pakabudhi, rot (potongan oajak/oengurangan oajak), padesi, pacaru, denda wsi, palilebleb, gana-gana, tarubana, tamtam, pamli, pargapan, babini, kamasan, saga, pakupat, paremrem, bakatbakat, patimtim, pamuncagiri, patalitali, pabarangka, parangsan, pakasumba, palawe, pasanga pasangu, pawidi, palakar pakatep padurupuling, pajak lek, pajnumanggala palengawatu, purbwapurbwa, palanting, pamucuk.

Jenis -jenis pajak tersebut berlaku pada zaman kerajaan saat itu. Hingga kini jenis pajak tersebut tidak berlaku. Untuk saat ini jenisnya disebut pepeson yang artinya yang harus dikeluarkan atau dihaturkan bagi setiap keluarga jika ada upacara atau sejenisnya seperti daun satu lipat, sayur kecipir/kelongkang 20 buah, jajan 20 bungkus, uang Rp. 25.000,-, beras $40 \mathrm{~kg}$ rata-rata dalam segala kegiatan baik penduduk maupun bukan penduduk Bengkala yang bertempat tinggal di kawasan itu.

\section{d. Hal Yang Dilarang Raja}

Melihat situasi masyarakat Bengkala yang resah dan kecewa serta tidak berdaya itu, maka dengan tegas raja memberi keringanan/pembebasan pajak kepada masyarakat Desa Bengkala sebagai berikut:

- $\quad$ Keputusan raja terkait dengan segala sesuatu agar tidak dipertentangkan untuk selamanya. Hingga kini, hal dimaksud adalah agar masyarakat Bengkala pada umumnya untuk mengikuti segala peraturan pemerintah yang menjadi aturan atau hukum tetap untuk dilaksanakan dengan baik oleh penduduk Bengkala. (2a.4)

- Untuk tidak dikenai berbagai macam biaya dan pajak apa pun oleh para petugas pemungut pajak hingga sekarang. Namun warga kolok Bengkala dengan ketulusan hati dan penuh kesadaran mulai sekitar tahun 2000-an ikut serta bergotong royong di lingkungan masyarakat Desa Bengkala. Bahkan ketika mulai acara bergotong royong tersebut yang 
paling pertama kali datang adalah warga kolok dan turut serta sebagai pengatur kendaraan, dan sebagai hansipnya. (2a.6)

- Pajak peternakan kuda pun tidak dikenai yang awalnya 4 kupang menjadi 2 kupang selanjutnya dibebaskan pajaknya.(2b.1)

- Jika ada yang praktik perdukunan di wilayah Bengkala maka tidak ditunjuk untuk tugas tugas upacara di Pujung dan Petatahan. Tidak dikenai kerja rodi/gotong royong dan diperkenankan mengunjungi desa lain yang memerlukannya dan tidak ditegur oleh para petugas di masa itu. (3b.3)

- Jika ada pesraman bagi Wiku/Rsi di desa itu, maka tidak dikenai sesajen/saji-sajian pantibhumi/pajak di Pura Panti dan tidak akan dipermasalahkan oleh watek kuturan/petugas pemungutnya dan tidak kena padesi (pajak desa) serta pacaru/upacara pecaruan. (3b.6).

\section{e. Hal yang Dibolehkan Raja}

Selain hal yang dilarang raja, maka ada hal yang diperbolehkan oleh raja sesuai dengan petunjuk prasasti sebagai berikut.

- Masyarakat Bangkala sewilayahdesanya diperkenankan pergi ke pasar menurut kehendaknya dan tidak ditegur oleh tapiaji dan tidak dipunguti lagam rwang/semacam cukai) Pada 3a.6 yang bunyinya :

.... masyarakat Desa Bengkala sewilayah desanya diperkenankan pergi ke pasar menurut kehendaknya dan tidak ditegur oleh tapiaji, tidak dipungut lagam rwang/cukai.

- Masyarakat Bengkala boleh memelihara itik dan tidak diambil oleh nayakan jawa. Pada $3 a .6-3 b$ 1) yang bunyinya:

... mereka boleh memelihara itik tidak akan diambil oleh nayakanjawa, tidak kena pacadar, panala, pajait, pabhangkudu, dan lain-lain semacam itu.

- Diijinkan memelihara asu tugel dan pirung tidak akan diambil oleh nayakan buru dan tidak dikenai posyan/pajak. (3b.1)

- Diijinkan untuk melakukan sambung ayam di wilayah bangunan suci/pura pada awal upacara jika memang diperlukan. Untuk seberapa banyak dilakukannya sambung ayam tidak dibatasi jumlahnya dan tidak perlu dimintakan ijin. (3b.2)

- Masyarakat dibolehkan menyembelih kerbau, sapi dan tidak dibatasi jumlahnya dan tidak perlu dimintakan ijin pada petugas. (4a.2).

- Masyarakat dibolehkan mencari sumber air, memperluas kali untuk pengairan (4a.4)

- Dibolehkan melakukan pekerjaan kotor atau berbahaya beserta mengumpulkan dan mengambil binatang dari hutan serta termasuk unyanunyan/ hiburan tidak perlu minta ijin.

- Dibolehkan menebang kayu-kayu larangan terutama pohon kemiri, pohon beringin boddi, pohon mindi jika kayu-kayu itu merusak yaitu menaungi sawah, kebun, lahan padi gaga, pagar rumah, tempat pertemuan, untuk memperbaiki jalan, walau sampai akarnya. (4a.5). 


\section{f. Hal yang Diatur Raja}

Bila terjadi sesuatu di Desa Bengkala dilaporkan kepada petugas, maka akan tidak dikenai biaya pelaporan dan berbagai macam saji-sajian (4b.3).

- $\quad$ Bila terjadi Salah pati tidak ada yang mengetahui tapi diketahui oleh pejabat caksu wruh maka dikenakan dosa tamtam 2 masaka 2 kupang dan tidak dikenai saji-sajian dan kelengkapannya. (4b.5)

- Bila ada tanda bahaya besar supaya menyerahkan partikel tanah masing-masing 1 masaka, jika buruk akibatnya harus mengadakan upacara korban penyucian selama sehari siang malam supaya memberikan daksina 1 masaka masing-masing tanpa dikenai saji-sajian. (4b.5)

- Bila ada warga yang salah jalan berbuat dosa ganagana segala jenis seperti merampok, mencuri hingga menyihir, meracun hingga darah tercecer, maka segala kejahatan diancam denda sebagai kejahatan besar harus membayar 1 masaka, pamli 2 kupang, temuan 2 kupang, setiap hari ke sembilan hingga dilakukan pecaruan. (4b. 6).

- Bila warganya memperistri golongan brahmana wangsa maka membayar pamucuk 2 kupang, denda 1 masaka untuk masing-masing.

Implementasi prasasti tersebut hingga kini terdapat beberapa hal yang telah ditetapkan Desa Bengkala terhadap warga kolok dalam masa kini menurut Suarbhawa sebagai berikut. Memberi inspirasi dan dipakai sebagai salah satu acuan dalam kehidupan masyarakat Bengkala saat ini. Memuat data historis berbagai tentang aspek kehidupan masyarakat Bengkala (Karaman Bangkala) pada masa lalu. Beberapa aspek kemasyarakat yang tersebut didalam prasasti, terdapat benang merah dengan kehidupan masyarakat Bengkala saat ini/dibuatkan monumen yang saat ini menjadi Pura Pasupati. Dijadikan hari jadi Desa Bengkala setiap tanggal 22 Juli. Munculnya kesenian yang terinspirasi dari prasasti Bengkala. Berbagai even olahraga yang berkait dengan hari jadi desa Bengkala. Menumbuhkan kebanggaan, persatuan kesatuan, jatidiri, persaudaraan serta kerukunan masyarakat desa Bengkala. Terkait dengan pendapat tersebut di atas, maka penjabaran dari prasasti itu dapat disampaikan bahwa prasasti Prasasti tersebut memberi daya yang menginspirasi masyarakat Bengkala hingga tertuang dalam awig-awig, ekalikita dan pararem desa. Menghimpun segenap data yang terkait dengan historikal/sejarah Desa Bengkala yang dapat dijadikan pedoman atau acuan bagi generasi selanjutnya. Hal yang penting dalam prasasti itu menjadi pedoman masyarakat Bengkala dalam kehidupan sehari-hari.

\section{Kesimpulan}

Yang menjadi kesimpulan dari hasil dan penjelasan di atas, dipandang dari dua hal yaitu. substansi yang ada pada Prasasti Desa Bengkala dan implementasi dari isi prasasti itu dalam kehidupan warga kolok di Desa Bengkala Kabupaten Buleleng. Untuk itu dijelaskan 1) yang menjadi substansi dari Naskah Prasasti Bengkala dengan menjabarkan ukuran dari Prasasti bengkala, isi Prasasti logam dengan alih bahasanya serta adanya prasasti batu dengan penjelasannya. 2) terkait dengan implementasi terhadap warga kolok di Desa Bengkala bahwa adanya kebijaksanaan pemimpin yang turut membantu warga kolok dari masa kerajaan, 
adanya jabatan pemimpin yang terkait dengan prasasti Bengkala, adanya jenis-jenis pajak, adanya hal yang dilarang dan hal yang dibolehkan.

\section{References}

[1] Darmaya, I Ketut. Tanpa Tahun. Sangsit Dalam Sejarah. Tanpa Tempat : Gapura (Gema Aliansi Pemerhati Budaya Bali Utara)

[2] Dharma Suteja, I Made. 1996. "Adaptasi Penyandang Tuli Bisu Di Desa Bengkala Kecamatan Kubutambahan Buleleng. (Suatu kajian Antropologi).” Denpasar : Jurusan Antropologi Fakultas Sastra Universitas Udayana.

[3] Tim Penyusun. 2009. "Laporan Penelitian Arkeologi, Survey Epigrafi Kubutambahan, Buleleng. Denpasar : Departemen Kebudayaan dan Pariwisata, Balai Arkeologi.

[4] Tim Penyusun. 2004.”Awig-Awig Desa Bengkala.” Buleleng : Desa Pakraman Bengkala.

[5] Vos, Connie de. 2012. Sign-Spatiality in Kata Kolok: How A Village Sign Language of Bali Inscribes Its Signing Space. Max Planck Institute for Phsycholiguistics Banjar Kederi Desa Singapadu Kaler Kecamatan Sukawati Kabupaten Gianyar (Perspektif Filosofi).

[6] Wijana, Nyoman. 2000. "Analisis Komposisi Komunitas Tumbuhan Dan Pemberdayaan masyarakat Tuli Bisu dalam Pengelolaan Ekofarming Lahan Kering Di Desa Bengkala Kecamatan Kubutambahan Kabupaten Buleleng.” Singaraja : Sekolah Tinggi Keguruan dan Ilmu Pendidikan.

[7] Suarbhawa, I Gusti Made dan I Nyoman Sunarya. 2004. Prasasti Desa Bengkala Kubutambahan Buleleng. Denpasar.

[8] http://dianmurdika.blogspot.com/2016/08/bengkala-desa-tua-dengan-beragam.html

[9] https://radarbali.jawapos.com/radar/uploads/radarbali/news/2017/09/08/berusia-10-abad-cegahkerusakan-prasasti-bengkala-dibikinkan-replika_m_12382.jpeg

[10] https://www.nusabali.com/berita/9019/kupas-isi-prasasti-bengkala-yang-dibuat-di-zaman-rajajaya-pangus

[11] https://beritabali.com/read/2016/11/23/201611230002/Membaca-Prasasti-Abad-ke-11-di-DesaBengkala.html

[12] https://id.m.wikipedia.org.wiki.prasasti

[13] digilib.unila.ac.id 